\title{
A QUEUEING MODEL FOR SOME CATALYTIC REACTIONS
}

\author{
Paraschiv Balea and Gheorghe Potcovaru
}

Department of Applied Mathematics, Faculty of Chemistry, Bucharest University, Bucharest, Romania

\section{ABSTRACT}

The waiting model associated to the catalytical process given by the chemical equation $C+S \stackrel{k_{1}}{\leftrightarrows} C S \stackrel{k_{3}}{\longrightarrow} C+P \quad(1)$, is described by the Markov process: $\left\{X_{i}(t) ; t \geq 0\right\},(i=1,2,3,4)$, where the random variables are the concentrations of the species $C$ (the catalyst), $S$ (the substrate), $C S$ (the intermediate complex formed by the substrate $S$ and the catalyst) and $P$ (the reaction product) at time $t$. The equations, that describe the evolution of the process, have been obtained.

KEYWORDS: waiting model, catalytic processes , Markov process.

\section{RESUMO}

o modelo de "fila de espera" associado com o processo catalitico descrito pela equacão

$$
C+S \frac{k_{l}}{k_{2}} C S \stackrel{k_{3}}{\longrightarrow} C+P(\eta)
$$

é descrito pezo processo de Markov $\left[x_{i}(t) ; t \geq 0\right]$,

$[i=r, 2,3,4]$, onde as variäveis casuisticas são as concentrafóes das espécies C (catalizador), S (substrato), CS (o complexo intermediário formado entre o substrato e o catalizador) e P (o produto da reaço) no tempo t. Foram obtidas as equacões que descrevem o processo.(I). 


\section{Introduction}

A catalytic reaction may be represented as follows

$$
C+S \underset{k_{2}}{\stackrel{k_{1}}{\leftrightarrows}} C S \stackrel{k_{3}}{\longrightarrow} C+P
$$

or, more explicitly,

$$
\left\{\begin{array}{l}
\left(T_{1}\right): C+S \stackrel{k_{1}}{\longrightarrow} C S \\
\left(T_{2}\right): C S \stackrel{k_{2}}{\longrightarrow} C+S \\
\left(T_{3}\right): C S \stackrel{k_{3}}{\longrightarrow} C+P
\end{array}\right.
$$

We have denoted by $C$-the catalyst, $S$-the substrate, $C S$-the intermediate complex formed by the substrate $S$ and the catalyst, $P$-the reaction product, $k_{i}(i=1,2,3)$-the rate constants of reaction associated with each step of the process.

1. It is probable that the catalyst's reaction with the substrate $S$ is reversible, forming the intermediate complex CS (the bimolecular process $T_{1}$ ) which may dissociate then into the initial reactants (the unimolecular transformation $T_{2}$ ) or may decompose into the reaction product and the catalyst in the initial form (the unimolecular decomposition $T_{3}$ ).

We suppose that the balance between the initial reactants and the complex $C S$ involves very fast reactions with respect to the decomposition step $\left(T_{3}\right)$, i.e. $k_{3} \ll k_{1}$ and $k_{3} \ll k_{2}$, so that the balance is not interrupted by an ordinary decomposition.

Many deterministic models for the kinetics of the catalytic processes were suggested and studied. The deterministic approach still has some deficiencies. Thus, the catalytic processes are developed for the individual molecular species and for the complexes. Actually, the transformations take place only for groups and it is interesting to find a mathematical model for which the number of moles per second is considered, from the mathematical point of view, a continuous variable.

In all the formulations used for a catalytic process involving one or more intermediates probabilistic laws are employed and these should be included in the mathematical model. This is not the case for the deterministic models. The deterministic approach of the catalytic processes does not take into account all the random fluctuations which frequently appear in practice.

In the mathematical model considered, some of these deficiencies typical to the deterministic models are removed by describing more accurately the 
catalytic process.

We shall consider the catalytic process as a waiting phenomenon. If we take into consideration the action of a catalyst molecule we see that after an "effective" collision with a molecule of the substrate $S$, it will be free to collide with another molecule of the substrate $S$.

This leads us to the idea of considering the catalyst molecules as "serving stations" and the molecules of the substrate $S$ as "clients". The transformation of a molecule of the $S$ substrate into the complex means serving one client.

The mechanism of the catalytic processes being generally complicated, its description by a waiting model which takes into consideration all the intervening factors is difficult, and therefore we shall consider a simpler case. We suppose that we introduce in a container $x_{10}$ catalyst molecules (the stations). We suppose that each catalyst molecule is capable at a certain moment of time to transform into intermediary complex $C S$ only a molecule of the $S$ substrate. From (2) we notice that the transformations $\left(T_{2}\right)$ and $\left(T_{3}\right)$ impose to the catalytic process a distinct feature from the point of view of the waiting theory namely the fact that the "serving" mechanism of the client by the station may be terminated either through the "unsatisfied" request (the complex $C S$ may dissociate into the substances $C$ and $S$ which formed it), or through the "satisfied" request, namely the effective serving of the client (the complex $C S$ may decompose in the reaction product $P$ with the catalyst $C$ ). In both cases, the station remains free so that the next client may be served.

Another feature of this model is that the catalyst molecules (the stations) and the molecules of substrate $S$ (the clients) have random motions, of Browmian type, changing permanently their positions. If we take into consideration that the number of inefficient collisions between a $C$ and an $S$ molecule is randomized, we deduce that serving is made on the principle "the first arrived is the first served". The whole arriving mechanism is hence random, because there might be more random collisions which did not lead to the formation of the complex before an effective collision. 


\section{$2 \quad$ Waiting Model}

The waiting model associated with the catalytic process given by the chemical equations (1) or (2) is described by the Markov process:

$$
\left\{X_{i}(t) ; t \geq 0\right\}(i=1,2,3,4)
$$

where the random variables $X_{i}(t)(i=1,2,3,4)$ are the concentrations of the species $C, S, C S$ and $P$ at time $t$.

The state space $X$ is the space of all the possible values $x_{i}(i=1,2,3,4)$ which might be taken by the random variable $X_{i}(t)(i=1,2,3,4)$.

We suppose that during the infinitesimal interval of time $(t, t+\Delta t)$ either one of the three processes can take place: the formation of the complex $C S$ $\left(T_{1}\right)$, or its dissociation $\left(T_{2}\right)$, or its decomposition to form the product $\left(T_{3}\right)$.

We denote by $\mu_{1}, \mu_{2}, \mu_{3}$ the stochastic parameters corresponding to the reaction rate constants $k_{1}, k_{2}, k_{3}$. The chemical process described by the equations (2) could be defined by using the following probabilities:

$1^{0} . \mu_{1} x_{1} x_{2} \Delta t+0(\Delta t)$, the probability that in the interval of time $(t, t+\Delta t)$ the complex $C S$ is formed through the transformation $\left(T_{1}\right)$, knowing that at the initial time $t=0$ there were $x_{10}$ and $x_{20}$ of the type $C$ and $S$ respectively and that at time $t(t>0)$ there were $x_{1}$ and $x_{2}$ molecules of $C$ and $S$, respectively.

$2^{0} \cdot \mu_{2} x_{3} \Delta t+0(\Delta t)$, the probability that in the interval of time $(t, t+\Delta t)$ the complex $C S$ dissociates by transformation $\left(T_{2}\right)$, knowing that at the time $t(t>0)$ there were $x_{3}$ molecules of the type $C S$.

$3^{0} . \mu_{3} x_{3} \Delta t+0(\Delta t)$, the probability that in the interval of time $(t, t+\Delta t)$ the complex $C S$ dissociates by means of transformation $\left(T_{3}\right)$, knowing that at the moment $t(t>0)$ there were $x_{3}$ molecules of type $C S$.

$4^{0} .0(\Delta t)$, the probability that in the interval of time $(t, t+\Delta t)$ more than one molecule of the type $C S$ is formed or that more than one molecule of the type $C S$ reacts to form $C$ and $S$ or $C$ and $P$.

$5^{0} .1-\left(\mu_{1} x_{1} x_{2}+\mu_{2} x_{3}+\mu_{3} x_{3}\right) \Delta t+0(\Delta t)$, the probability that in the time interval $(t, t+\Delta t)$ there is no change in the concentrations of the species $C$, $S, C S$ and $P$, knowing that at the moment $t(t>0)$ there were $x_{i}(i=1,2,3)$ molecules of type $C, S$ and $C S$.

The process defined above, not being linear with respect to the concentrations $x_{i}$ of the reacting species, is not a simple process of birth and death. The concentrations of the species $C, S, C S$ and $P$ are statistically indepen- 
dent. Let.

$$
P\left(x_{1}, x_{2}, x_{3}, x_{4} ; t\right)=P\left\{X_{i}(t)=x_{i}, i=1,2,3,4\right\}
$$

be the probability that at the moment $t(t>0)$ there are in the system $x_{1}$ molecules of the catalyst species $C, x_{2}$ molecules of the substance $S, x_{3} C S$ complex molecules and $x_{4}$ molecules for the reaction product $P$.

Using the probabilities $1^{0}-5^{0}$ we may write the equation:

$$
\begin{aligned}
& P\left(x_{1}, x_{2}, x_{3}, x_{4} ; t+\Delta t\right)=\left[1-\left(\mu_{1} x_{1} x_{2}+\mu_{2} x_{3}+\mu_{3} x_{3}\right) \Delta t\right] P\left(x_{1}, x_{2}, x_{3}, x_{4} ; t\right)+ \\
& +\mu_{1}\left(x_{1}+1\right)\left(x_{2}+1\right) \Delta t P\left(x_{1}+1, x_{2}+1, x_{3}-1, x_{4} ; t\right)+ \\
& +\mu_{2}\left(x_{3}+1\right) \Delta t P\left(x_{1}-1, x_{2}-1, x_{3}+1, x_{4} ; t\right)+ \\
& +\mu_{3}\left(x_{3}+1\right) \Delta t P\left(x_{1}, x_{2}, x_{3}+1, x_{4}-1 ; t\right) \Delta t
\end{aligned}
$$

Taking into consideration also that

$$
x_{1}=x_{10}-x_{3}, x_{4}=x_{20}-\left(x_{2}+x_{3}\right)
$$

it follows that:

$$
\begin{aligned}
& P\left(x_{2}, x_{3} ; t+\Delta t\right)=\left\{1-\left[\mu_{1} x_{2}\left(x_{10}-x_{3}\right)+\mu_{2} x_{3}+\mu_{3} x_{3}\right] \Delta t\right\} P\left(x_{2}, x_{3} ; \Delta t\right)+ \\
& +\mu_{1}\left(x_{10}-x_{3}+1\right)\left(x_{2}+1\right) \Delta t P\left(x_{2}+1, x_{3}-1 ; t\right)+ \\
& +\mu_{2}\left(x_{3}+1\right) \Delta t P\left(x_{2}-1, x_{3}+1 ; t\right)+ \\
& +\mu_{3}\left(x_{3}+1\right) \Delta t P\left(x_{2}, x_{3}+1 ; t\right)+0(\Delta t)
\end{aligned}
$$

Substituting in the first term $P\left(x_{2}, x_{3} ; t\right)$, dividing by $\Delta t$ and taking the limit $\Delta t \rightarrow 0$, we get the partial derivative equation:

$$
\begin{aligned}
& \frac{\partial P\left(x_{2}, x_{3} ; t\right)}{\partial t}=-\left[\mu_{1} x_{2}\left(x_{10}-x_{3}\right)+\mu_{2} x_{3}+\mu_{3} x_{3}\right] P\left(x_{2}, x_{3} ; t\right)+ \\
& +\mu_{1}\left(x_{10}-x_{3}+1\right)\left(x_{2}+1\right) P\left(x_{2}+1, x_{3}-1 ; t\right)+ \\
& +\mu_{2}\left(x_{3}+1\right) P\left(x_{2}-1, x_{3}+1 ; t\right)+\mu_{3}\left(x_{3}+1\right) P\left(x_{2}, x_{3}+1 ; t\right)
\end{aligned}
$$


We introduce the generating function:

$$
G\left(s_{2}, s_{3} ; t\right)=\sum_{x_{2}=0}^{x_{20}} \sum_{x_{3}=0}^{x_{30}} P\left(x_{2}, x_{3} ; t\right) s_{2}^{x_{2}} s_{3}^{x_{3}},\left|s_{2}\right| \leq 1,\left|s_{3}\right| \leq 1
$$

Multiplying in the equation (3) by $s_{2}^{x_{2}} s_{3}^{x_{3}}$ and suming over $x_{2}$ and $x_{3}$, we obtain the partial derivative equation:

$$
\begin{aligned}
& \frac{\partial G\left(s_{2}, s_{3} ; t\right)}{\partial t}=\mu_{1} x_{10}\left(s_{3}^{2}-s_{2}\right) \frac{\partial G\left(s_{2}, s_{3} ; t\right)}{\partial s_{2}}+\left(\mu_{3}+\mu_{2} s_{2}-\mu_{2} s_{3}-\mu_{3} s_{3}\right) \\
& \frac{\partial G\left(s_{2}, s_{3} ; t\right)}{\partial s_{3}}+\mu_{1} s_{3}\left(s_{2}-s_{3}\right) \frac{\partial^{2} G\left(s_{2}, s_{3} ; t\right)}{\partial s_{2} \partial s_{3}}
\end{aligned}
$$

Aplying the cumulative generating function:

$$
K(u, v ; t)=\log G\left(s_{2}, s_{3} ; t\right)
$$

to equation (4) we get:

$$
\begin{aligned}
& \frac{\partial K(u, v ; t)}{\partial t}=\mu_{1} x_{10}\left(e^{2 v-u}-1\right) \frac{\partial K(u, v ; t)}{\partial u}+ \\
& +\left(\mu_{2} e^{u-v}+\mu_{3} e^{-v}+\mu_{2}-\mu_{3}\right) \frac{\partial K(u, v ; t)}{\partial v}+ \\
& +\mu_{1}\left(1-e^{v-u}\right) \frac{\partial^{2} K(u, v ; t)}{\partial u \partial v}+\mu_{1}\left(1-e^{v-u}\right) \frac{\partial K(u, v ; t)}{\partial u} \frac{\partial K(u, v ; t)}{\partial v}
\end{aligned}
$$

On the other hand, using the relation between the differential cumulant generating function and the moments of the random variables $X_{2}(t)$ and $X_{3}(t)$ and the usual notations, we obtain:

$$
\begin{aligned}
K(u, v ; t)= & u M\left(X_{2}(t)\right)+v M\left(X_{3}(t)\right)+\frac{1}{2} u^{2} D^{2}\left(X_{2}(t)\right)+\frac{1}{2} v^{2} D^{2}\left(X_{3}(t)\right)+ \\
& +u v \operatorname{Cov}\left(X_{2}(t), X_{3}(t)\right)+\cdots
\end{aligned}
$$

Calculating the partial derivatives:

$$
\frac{\partial K(u, v ; t)}{\partial t}, \frac{\partial K(u, v ; t)}{\partial u}, \frac{\partial K(u, v ; t)}{\partial v}, \frac{\partial^{2} K(u, v ; t)}{\partial u \partial v}
$$


and substituting them into (5) we get:

$$
\begin{aligned}
& \frac{d M\left(X_{2}(t)\right)}{d t}=-\mu_{1} x_{10} M\left(X_{2}(t)\right)+\mu_{2} M\left(X_{3}(t)\right)+ \\
& +\mu_{1} \operatorname{Cov}\left(X_{2}(t), X_{3}(t)\right)+\mu_{1} M\left(X_{2}(t)\right) M\left(X_{3}(t)\right) \\
& \frac{d M\left(X_{3}(t)\right)}{d t}=2 \mu_{1} x_{10} M\left(X_{2}(t)\right)-\left(\mu_{2}-\mu_{3}\right) M\left(X_{3}(t)\right)- \\
& -\mu_{1} \operatorname{Cov}\left(X_{2}(t), X_{3}(t)\right)-\mu_{1} M\left(X_{2}(t)\right) M\left(X_{3}(t)\right)+2 \mu_{2} D^{2}\left(X_{3}(t)\right) \\
& \frac{d D^{2}\left(X_{2}(t)\right)}{d t}=2 \mu_{1}\left[M\left(X_{3}(t)\right)-x_{10}\right] D^{2}\left(X_{2}(t)\right)+\mu_{1} x_{10} M\left(X_{3}(t)\right)- \\
& -\mu_{1} M\left(X_{2}(t)\right) M\left(X_{3}(t)\right)+\left[2 \mu_{2}-\mu_{1}+2 M\left(X_{2}(t)\right)\right] \operatorname{Cov}\left(X_{2}(t), X_{3}(t)\right) \\
& \frac{d D^{2}\left(X_{3}(t)\right)}{d t}=-2\left[\mu_{2}+\mu_{3}+\mu_{1} M\left(X_{2}(t)\right)\right] D^{2}\left(X_{3}(t)\right)+4 \mu_{1} x_{10} M\left(X_{2}(t)\right)+ \\
& +\left(\mu_{2}+\mu_{3}\right) M\left(X_{3}(t)\right)-\mu_{1} M\left(X_{2}(t)\right) M\left(X_{3}(t)\right)+ \\
& +\mu_{1}\left[4 x_{10}-1-2 M\left(X_{2}(t)\right)\right] \operatorname{Cov}\left(X_{2}(t), X_{3}(t)\right) \\
& \frac{d \operatorname{Cov}\left(X_{2}(t), X_{3}(t)\right)}{d t}=\left\{\mu_{1}\left[1-x_{10}-M\left(X_{2}(t)\right)+M\left(X_{3}(t)\right)\right]-\mu_{2}-\mu_{3}\right\} \\
& \operatorname{Cov}\left(X_{2}(t), X_{3}(t)\right)+\mu_{1}\left[2 x_{10}-M\left(X_{3}(t)\right)\right] D^{2}\left(X_{2}(t)\right)+ \\
& +\left[\mu_{1}+x_{10} M\left(X_{2}(t)\right)+\mu_{2}+\mu_{1} M\left(X_{2}(t)\right)\right] D^{2}\left(X_{3}(t)\right)- \\
& -2 \mu_{1} x_{10} M\left(X_{2}(t)\right)-\mu_{2} M\left(X_{3}(t)\right)
\end{aligned}
$$


which are exactly the equations describing the evolution of the catalytic process with time.

The stochastic model presented may be considered an extension of the deterministic model known in chemical kinetics.

\section{REFERENCES}

1. P. Balea, Polytechnic Institute of Bucharest, Scientific Bulletin, Mechanical Engineering, LIII (1-2), 19-21 (1991).

2. P. Balea, Polytechnic Institute of Bucharest, Scientific Bulletin, Mecanica, XIII (2), 10-15 (1980).

3. A. F. Bartholomay, Biochemistry, (1-2), 223-230 (1962).

4. T.A. Bharucha-Reid, "Elements of the Theory of Markov Processes and Their Applications", Mc. Graw-Hill Book Company, Inc., New York, N. Y., USA, pp. 115-127 (1960).

5. W. Feller, "An Introduction to Probability Theory and Its Application $s "$, John Wiley, New York, Vol. 1, pp. 23-40 (1957).

6. L. G. Ionescu, S. Dani and E. F. Souza, South. Braz. J. Chem., 8, 9, 85 (2000).

7. M. Iosifescu and P. Tăutu, "Procese Stochastice şi Aplicaţii în Biologie şi Medicină", Ed. Acad. Republicii Socialiste Romania, Bucureşti, pp.87-92 (1968).

8. L. Takacs, "Combinatorial Methods in the Theory of Stochastic Process -es", John Wiley, New York, N.Y., USA (1967). 